\title{
DOCEAMUS
}

doceamus ... let us teach

\section{The CBMS 2010 Survey}

\section{Ellen Kirkman}

Every five years, beginning in 1965, a survey of undergraduate mathematical science departments has been undertaken under the auspices of the Conference Board of the Mathematical Sciences (CBMS), with funding from the National Science Foundation. The written report of the most recent survey, CBMS2010, now is available online at http: //www. ams . org/cbms and in print from the AMS. This article is an introduction to the survey report, which is designed to aid academic planners and department chairs seeking national comparison data. Here we present samples of the kinds of data available in the survey report and encourage readers to explore the full report.

In the fall semester of 2010, an online questionnaire was sent to a stratified simple random sample of mathematical science departments (with separate instruments for four-year mathematics departments, statistics departments with an undergraduate program, and mathematics programs at two-year colleges), collecting individual course enrollments, data on how courses were taught, numbers of degrees awarded, and demographics of faculty and students-enabling comparison of the 2010 data with that from previous surveys. Enrollment data were broken down into distancelearning enrollments and nondistance-learning enrollments; all data from four-year mathematics departments were broken down by the highest degree awarded by the department (bachelor's,

Ellen Kirkman is professor of mathematics at Wake Forest University in Winston-Salem, NC. Her email address is kirkman@wfu.edu.

Members of the Editorial Board for Doceamus are: David Bressoud, Roger Howe, Karen King, William McCallum, and Mark Saul.

DOI: http://dx.doi.org/10.1090/noti1060 master's, or doctoral). In addition to the data collected every five years, questions on special topics of current interest to the profession were also a part of the survey.

The 2010 survey found that, while from 1995 to 2010 four-year mathematics enrollments have not grown as fast as general four-year college and university enrollments, in the most recent five-year period, from 2005 to 2010, enrollments in mathematical science departments increased by about 26 percent, while general college enrollments grew by about 13 percent [1, Table S.1]. The enrollment growth was observed generally across all categories of courses, including advanced-level mathematics courses (where total enrollment for all levels of mathematics departments combined increased 35 percent), and for all levels of institutions (for example, advanced-level mathematics course enrollment increased 24 percent at the doctoral-level mathematics departments) [1, Table E.3]. The 2005 CBMS survey had reported a decline from the 2000 CBMS survey in mathematics enrollments, and that report had expressed concern over the limited availability of advancedlevel undergraduate mathematics courses. However, the 2010 survey found greater availability; for example, the percentage of all four-year mathematics departments offering each of the following courses within a two-academic-year time period was: Modern Algebra I, 80 percent for 2009-11 (61 percent for 2004-6); Modern Algebra II, 27 percent for 2009-11 (21 percent for 2004-6); Advanced Calculus-Real Analysis I, 79 percent for 2009-11 (66 percent for 2004-6); Advanced Calculus-Real Analysis II, 31 percent for 2009-11 (26 percent for 2004-6) [1, Table SP.23]. The 2010 survey found that the largest growth in an enrollment category occurred in elementary statistics courses, 
where enrollments in courses taught in four-year mathematics departments (which were almost three times those in statistics departments) increased about 56 percent from 2005 to 2010 [1, Table S.2].

In contrast to increasing mathematics enrollments, the number of bachelor's degrees awarded by mathematics departments declined slightly from 2004-5 to 2009-10; the percentage of these degrees awarded to women was 43 percent for the 2009-10 academic year, up from 40 percent in 2004-5 (it was 43 percent in 1999-2000). Continuing a trend observed in the 2005 survey, the total number of bachelor's degrees in the mathematical sciences awarded by doctoral-level departments increased (up 8 percent over 2005), while the total number of degrees awarded by master's-level and bachelor's-level departments each decreased [1, Table E.1]. If one excludes degrees in computer science awarded through mathematics departments, the doctoral-level mathematics departments awarded the largest percentage of the bachelor's degrees awarded by four-year mathematics departments (44 percent), a trend that began in 2005; in the previous surveys the bachelor's-level departments had awarded the largest percentage of the mathematical science degrees [1, Figure E.1.4 and Table E.1].

The growth in enrollment observed in the 2010 survey was not matched by a growth in the number of faculty. In mathematics departments at fouryear institutions, the number of full-time plus part-time faculty was almost the same in the 2005 and 2010 surveys, though the number of part-time faculty continued the decline observed from the 2000 to 2005 survey [1, Table S.14]. As has been noted in yearly reports from the Data Committee that are published in the Notices of the AMS, much of the growth in faculty has been in the category of "other full-time faculty" (full-time faculty who are not tenure-eligible). Some, but not all, of the increase in "other full-time faculty" was due to the increase in the number of postdoctoral positions (defined to be "temporary positions primarily intended to provide an opportunity to extend graduate training or to further research experience"). For example, in the doctoral mathematics departments, the number of other full-time faculty (including postdocs) increased 22 percent from 2005 to 2010, while the number of other full-time faculty, excluding postdoctoral positions, was up 16 percent; at bachelor's-level departments other full-time positions were up 58 percent from 2005 to 2010 (almost all such positions are not postdoc positions). In the doctoral-level mathematics departments the total number of tenured plus tenure-eligible faculty decreased slightly; however, the number of women in tenured or tenure-eligible positions in doctoral-level departments increased about 23 percent [1, Table F.1].
Special topics studied in the 2010 survey report included data on the mathematical education of precollege teachers, practices in dual and distance-learning courses, requirements for majors, estimates of the postgraduation plans of graduates, departmental assessment practices, and pedagogical issues in teaching college algebra and elementary statistics (the questions on teaching elementary statistics were also on the statistics department questionnaire, allowing comparison between practices at the two kinds of departments). Two chapters of the report present data on mathematics programs at two-year colleges, where enrollments increased 19 percent over 2005 [1, Table S.1], 21 percent if dual enrollment courses are included [1, Table TYE.2].

Distance-learning courses were defined to be "those courses in which the majority of instruction occurs with the instructor and students separated by time and/or place (e.g., courses in which the majority of the course is taught online, or by computer software, by television, or by correspondence)". The 2010 survey found that of four-year mathematics programs, distance-learning courses in the mathematical sciences were offered by 48 percent of the doctoral-level departments, 57 percent of the master's-level departments, and 28 percent of the bachelor's-level departments, but by 88 percent of two-year college mathematics programs. Further, of those departments offering distancelearning courses, 55 percent of the doctoral-level, 32 percent of the master's-level, 37 percent of the bachelor's-level, and 42 percent of the two-year college departments stated that the majority of tests were given at proctored testing sites. Across all levels of four-year mathematics departments, the instructional materials were said to be primarily created by faculty (as opposed to commercially produced) at 39 percent of the four-year college mathematics departments and 10 percent of the two-year college programs [1, Table SP.10].

Plans for the 2015 CBMS survey are under way currently, and suggestions for the 2015 survey are welcome.

\section{References}

[1] Richelle Blair, Ellen E. Kirkman, James W. MAXWELL, Statistical Abstract of Undergraduate Programs in the Mathematical Sciences in the United States, Fall 2010 CBMS Survey, American Mathematical Society, Providence, RI, 2013. Available at http://www . ams . org/cbms 